Instructions for authors, subscriptions and further details:

http://brac.hipatiapress.com

\title{
José Luis Guerin: Descubriendo una Sintaxis Posible
}

Juan Martínez Villegas ${ }^{1}$

1) Facultad de Bellas Artes. Universidad de Barcelona. España

Date of publication: June $3^{\text {rd }}, 2014$

Edition period: February 2014-June 2014

To cite this article: Villegas, J. M. (2014). José Luis Guerin: Descubriendo una sintaxis posible. Barcelona, Research, Art, Creation, 2(2), 169-200. doi: 10.4471/brac.2014.08

To link this article: http://dx.doi.org/10.4471/brac.2014.08

\section{PLEASE SCROLL DOWN FOR ARTICLE}

The terms and conditions of use, except where otherwise noted, are related to the Open Journal System and to Creative Commons Attribution License (CCBY). The indication must be expressly stated when necessary. 
BRAC - Barcelona Research Art Creation. Vol. 2 No. 2, June 2014, pp. 169-200

\section{José Luis Guerin: Discovering another Possible Syntax}

Juan Martínez Villegas

University of Barcelona

(Received: 15 January 2014; Accepted: 20 February 2014; Published: 3 June 2014)

\section{Abstract}

José Luis Guerin has called his work as sketched cinema. From this open definition, the possible language connections between the sketched image in two of his films, Unas Fotos en la Ciudad de Silvia (2007) and Guest (2010), and the fragmented narrative that he experienced in his two audiovisual installations created to date, Las mujeres que no conocemos (2007) and La Dama de Corinto (2011), are suggested. We analyze and contrast with the film maker the status of his poetic image, in relation to his diving into contemporary art, contextualizing his search for another possible syntax within the artistic practices of those authors working in the spaces of confluence between cinema and other arts.

Keywords: Guerin, poetic image, multi-projection installation, expositive cinema, fragmented narrative, hybridization, contemporary art, sketched cinema. 
BRAC - Barcelona Research Art Creation. Vol. 2 No. 2, June 2014, pp. $169-200$

\section{José Luis Guerin: Descubriendo una Sintaxis Posible}

Juan Martínez Villegas

Universidad de Barcelona

(Recibido: 15 Enero 2014; Aceptado: 20 Febrero 2014; Publicado: 3 Junio 2014)

\section{Resumen}

José Luis Guerin ha denominado su trabajo como cine esbozado. Desde esta definición abierta, se sugieren las posibles conexiones de lenguaje entre la imagen esbozada en dos de sus films; Unas Fotos en la Ciudad de Silvia (2007) y Guest (2010) y la narrativa fragmentada, que experimenta en sus dos instalaciones audiovisuales hasta la fecha; Las mujeres que no conocemos (2007) y La Dama de Corinto (2011). Analizamos y contrastamos con el director la entidad de su imagen poética, en relación con su incursión en el arte contemporáneo, contextualizando su búsqueda de otra sintaxis posible, dentro de las prácticas artísticas de aquellos autores que trabajan en los espacios de confluencia entre el cine y otras artes.

Palabras clave: Guerin, imagen poética, instalación, multi-proyección, cine expositivo, narrativa fragmentada, hibridación, arte contemporáneo, cine esbozado. 
on la aparición de José Luis Guerin en el panorama del cine español, han surgido numerosos análisis de la evolución del trabajo del director. Desde su primer largometraje Los motivos de Berta (1983), hasta sus últimas obras expuestas en salas de arte, Las mujeres que no conocemos (Pabellón de España, Bienal de Venecia 2007) y La Dama de Corinto, un esbozo cinematográfico (Museo Esteban Vicente de Segovia 2011), Guerin traza un recorrido de correspondencias en las que se intuye la vinculación de su imagen cinematográfica con el arte contemporáneo.

El director experimenta con instalaciones multipantalla, la relación entre su imagen fílmica y el punto de vista del espectador. Realiza con ello una extensión formal y conceptual de su trabajo, dando un paso más allá en la fragmentación de sus montajes, que de por sí tienden a la no linealidad, un aspecto inherente a sus películas.

La motivación del presente escrito es el acercamiento a la mirada sensible del cineasta y a su singularidad, ya que la incursión en el arte contemporáneo no la planifica, más bien responde a la llamada de los comisarios, en la actual inclinación por incorporar las hibridaciones de la imagen cinematográfica en los circuitos expositivos.

Se exponen las posibles conexiones de lenguaje entre dos de sus obras, en las que la recolección de gestos y la mirada lírico-documental inundan el contenido; Unas Fotos en la Ciudad de Silvia (2007) y Guest (2010), con sus dos instalaciones audiovisuales Las mujeres que no conocemos (2007) y La Dama de Corinto (2011). Se orientan estos vínculos en factores comunes, como son los medios, la herramienta utilizada, la narrativa no lineal y la tendencia del director en captar, reinterpretar y dotar de espacio propio a la imagen poética.

Basamos esta relación no tanto en las estrategias expositivas, como en el germen contenido en el trabajo de un autor que oscila entre los dos campos. Situamos sus instalaciones en el ámbito de las prácticas de artistas y cineastas, que trabajan con la expansión de la imagen múltiple. Se apoyan los argumentos en diversos estudios que han analizado el fenómeno desde varias perspectivas, así como en la obra de otros autores que provienen del arte o la cinematografía, planteando las posibles fricciones que se producen en estas experiencias de hibridación. 


\section{Martinez Villegas - Guerin: Descubriendo una sintaxis posible}

Para contrastar estos planteamientos, incluimos como Anexo la conversación inédita mantenida con el director, en la que hacemos una aproximación a la evolución de su singular obra. Le preguntamos el porqué de su incursión en el arte contemporáneo y su opinión acerca de la inclusión del cine en museos y salas de arte, diferentes aspectos de su pensamiento cinematográfico y artístico, los métodos con los que elabora su imagen, y la relación que guardan algunas de sus obras aparentemente dispares entre sí.

\section{La Imagen Poética y el Cine Esbozado}

El director ha denominado la orientación de su trabajo como cine esbozado, invitando al espectador a participar en ese proceso abierto. El sentido de la palabra esbozo en sus posibles acepciones, se refiere a la proyección de una intención que potencialmente podría desarrollarse: "Dibujo inacabado y esquemático de un proyecto artístico; Aquello que puede alcanzar mayor desarrollo y extensión; Tejido, órgano o aparato embrionario que todavía no ha adquirido su forma y estructura definitivas; Insinuación de un gesto". ${ }^{1}$ Cuando observamos un trazo primario en cualquier arte, éste nos remite a un momento bruto, una imagen intuida en el proceso de una obra, que más tarde se completa o no.

La denominación cine esbozado nos habla de la libertad para decidir hasta qué punto se cierra una escena, o de la invitación al espectador para completar lo que deliberadamente se le muestra indefinido. La secuencia poética de Guerin puede leerse como una imagen-gesto, que contiene una semilla, una idea abierta. Son aspectos de su obra que pertenecen al ámbito procesual, de pura creación, en el que la expresión depende de una mirada y de una cámara, que recoge algo que está fuera de él, pero de algún modo le pertenece. Momentos en los que la poesía surge.

Sus películas se interesan especialmente por lo que, en un cine "clásico", hubiera sido cortado en el montaje - o ni siquiera rodado. Graba y monta lo que habitualmente no se enseña (como la orina de una niña que se desliza sobre la tierra seca de un campo árido - ver Los motivos de Berta). El cineasta parece interesarse menos por lo que ocurre en la imagen que por lo que les ocurre a las imágenes y al tiempo del film. José Luis Guerin se interesa por lo que pasa cuando no pasa nada. (Mayer, 2010) 
Se podría hacer un glosario de imágenes esbozadas, que conforman el imaginario del autor. Estos hallazgos surgen del impulso de la intuición, son pequeños acontecimientos que se producen en los procesos de creación. Pero a veces el gesto trasciende su condición de aparente aleatoriedad azarosa, para mostrarse como imagen poética, denotando una realidad de nuestro mundo, que a menudo pasa desapercibida a la mirada.

Esta trascendencia del gesto bruto al poema visual, es tratada por Gaston Bachelard (1975). El filósofo se refiere a la creación literaria de la imagen poética, vinculando su autenticidad con el impulso de la imaginación:

La imagen poética es un resaltar súbito del psiquismo (...) surge en la conciencia como un producto directo del corazón, del alma, del ser del hombre captado en su actualidad (...) siempre es necesario un impulso sincero, un pequeño impulso de admiración para recibir el provecho fenomenológico de una imagen poética. La menor reflexión crítica detiene este impulso, situando al espíritu en posición secundaria, lo cual destruye la primitividad de la imaginación. (pp. 7, 8, 15)

Los bocetos que Guerín capta y recolecta, ocupan un lugar propio en su trabajo. En palabras de Gonzalo de Lucas (2011) “La conjetura, la ensoñación, la especulación daban paso a sus películas, que no sólo son búsquedas de lo que comúnmente llamamos imágenes -la representación fotográfica, física, de un objeto- sino de imágenes poéticas y asociaciones mentales o metafóricas $[\ldots] "$

Con esta actitud sensible, el director se adentra, en los terrenos del arte más intimista, el que se ejerce en la soledad de la imaginación, utilizando las herramientas simples pero profundas de la percepción de la imagen inédita, logrando pequeñas piezas etéreas, libres, que contienen la esencia de infinitas lecturas, repletas de evocaciones no sujetas a medidas de tiempo ni a circunstancia alguna, ni siquiera al ritmo de la narración. Gestos independientes, montados posteriormente siguiendo sus relaciones sutiles, desvinculándose así de la lógica lineal, del habitual lenguaje cinematográfico.

\section{El estimulante conflicto de Guest}

En el fondo Guest es la historia de un desplazado que busca nuevos caminos $[. .$.$] Guerin no quiere "reinventarse" a toda costa, como parece$ 


\section{Martinez Villegas - Guerin: Descubriendo una sintaxis posible}

estar de moda, y la transición le resulta lenta, dolorosa, contradictoria, lo que hace de Guest una experiencia apasionante para quien sepa ver esas dudas inscritas en cada plano, en cada paso de uno a otro. (Losilla, 2011)

Guest (J.L. Guerin, 2010), discontinuo diario de viaje, labor solitaria y artesanal, en el que el cineasta impregna de una mirada lírica cada plano documental que recoge, sirviéndose de transiciones poéticas, que hilan sutilmente la narrativa fraccionada. Las historias que componen Guest están conformadas en diferentes partes del planeta, en una constante tensión, entre la artificialidad de los festivales de cine a los que es invitado, y la autenticidad de los personajes marginales de las zonas periféricas de las ciudades que visita. En Guest la secuencia documental es a su vez imagen poética. Guest es la calle, la mirada, es ver y explicar el mundo a través de un objetivo, recogiendo el testigo de documentalistas de diarios filmados, como el lituano afincado en Nueva York, Jonas Mekas (con el que tiene un revelador encuentro en la propia película, que años después se materializa como correspondencia fílmica en la exposición Todas las cartas). Guerin recolector, percibe y capta pequeñas historias potenciales para un recorrido posterior.

Sus hallazgos visuales en Guest poseen la mirada sorprendida de los niños, la indiscreción del deseo, que irrumpe y delata sin pedir permiso, la fenomenología de lo pequeño, la captación de lo singular. Sorprendiéndose ante el fenómeno que observa y ante los paisajes humanos, desoladores o favorecidos, dentro de una favela o a través de un vaso que tiembla a bordo de un avión, en la presencia melancólica de un pato, atado en una calle decadente de La Habana, o en el reflejo del agua que se confunde con el mar, en el interior de un canal veneciano.

$\mathrm{Su}$ imagen poética es independiente de los temas que subyacen en la película: una mirada del mundo globalizado e injustamente repartido, el adormecimiento de las conciencias occidentales y el silencio de nuestras voces, que contrasta con la voz elocuente de las calles latino americanas. Personas que muestran sus vidas abriendo sus casas, relatando su particular visión de las cosas, predicadores con discursos similares en las diferentes partes del mundo, o la mirada de los niños, pura y sorprendida siempre, a pesar de la dureza de sus circunstancias.

Guerin escucha, a personas, objetos y fenómenos. Observa, reacciona y registra, evidenciando la realidad de los lugares que visita, y el contraste que su presencia misma provoca. 
La esencia del gesto grabado es explicada de forma sentida por Jonas Mekas en la película:

\begin{abstract}
(...) yo no elijo, respondo al momento. Reacciono a la vida. Voy caminando por las calles y decido: "Ahora debería filmar." Reacciono a lo que veo, no es una cuestión de pensar. Nada viene de aquí -señalando su cabeza-, viene de... Es automático. Es intuitivo... aleatorio, a veces. Un poco al azar. Azar... Y a ver qué pasa. El uso del azar también es una elección, por supuesto. Todo es elección y nada lo es realmente. Es de locos, dicho así. Está predeterminado. Crees que eliges, pero no creo que haya elección. Tú crees: "Esto es lo que yo elijo", pero ya ha sido predeterminado por las circunstancias, y por eso decides elegir eso. Algunas decisiones se toman aquí y algunas aquí -señalando cabeza y corazón-. Y otras se toman allí -señalando el cielo-. ${ }^{2}$
\end{abstract}

Las palabras del artista lituano nos traen las reflexiones de Bachelard. Desde aquí podemos mirar el movimiento y la causalidad que unifica el film. Todo se envuelve de esta manera de actuar: intuición, gesto y empatía hacia el objeto con el que interacciona. Consiguiendo que la cámara -agente condicionante situado entre el que graba y el grabado- sea casi invisible. Esta disposición es también la que facilita comprender los fenómenos que actúan como transiciones poéticas. Sirva para ilustrar el argumento, la breve escena de una niña sentada en el suelo, contenida en las secuencias grabadas en Palestina; el director baja la cámara hasta la altura de su mirada, pudiendo ver que las gallinas que pasan, son más altas que ella, recogiendo y haciéndonos partícipes de su punto de vista, evocándonos nuestra propia infancia. Este breve esbozo, sensible y poético anuncia el espléndido pasaje de los niños palestinos, que con su imaginación reconstruyen para la cámara la antigua escuela, sustituida por las ruinas del paisaje desolado en el que habitan.

El orden secuencial que podemos reconocer en Guest, se construye en función de dar forma de film a las escenas recolectadas. La relación entre las partes viene determinada por un guion, que se va manifestando de manera simultánea al descubrimiento de las historias que lo compondrán, y a los vínculos que existen entre ellas. Encontramos abundantes esbozos que nos presentan pequeños fenómenos - libretas de apuntes, soles y cielos variados, vistas difusas desde un tren en marcha, planos abstractos aéreos tomados en los aviones, reflejos de cristal o agua, miradas a través de los vidrios de las habitaciones, etcétera, actuando como transiciones de los fragmentos 


\section{Martínez Villegas - Guerin: Descubriendo una sintaxis posible}

documentales.

Si bien es cierto que estas imágenes ejercen de nexo entre las historias, es difícil distinguir entre poética y documental. Resulta trivial diferenciar los planos documentales centrados en la atención del sujeto grabado, de los hallazgos de una mirada, que por momentos abandona lo concreto, para entrar en lo sutil. El grueso de las secuencias contenidas en Guest, están impregnadas de esa atmósfera intangible. No es por tanto el uso del blanco y negro, el orden cronológico del diario de viaje o la herramienta (pequeña cámara de video digital), los únicos agentes que unifican y globalizan las diferentes partes del film; la mirada alerta al fenómeno y la disposición poética del autor, nos sugiere y conduce una trama posible dentro de la narrativa no lineal.

Para establecer los vínculos existentes entre las secuencias de este relato múltiple, el montaje toma un gran peso en la creación final. Imaginamos la difícil selección del material filmado (unas 150 horas recolectadas según el autor) y su relación interna, para facilitar que se revele el sentido último del film. Este es uno de los puntos de conexión con una de sus anteriores obras.

\section{El devenir de Unas fotos en la ciudad de Sylvia}

El material secuencial de imágenes fijas, utilizado en Unas fotos en la ciudad de Sylvia (J.L Guerín. 2007), marca una notable diferencia con el resto de obras del director, siendo su film más radical y experimental, pero también el más clásico en el sentido de indagar en el origen del cine, cuando la imagen aún carecía de movimiento. Sin embargo la condición solitaria de diarios de viaje (verdad o artificio pero diarios al fin y al cabo), compuestos a partir de gestos recolectados, la relaciona íntimamente con Guest, abriéndole un campo de trabajo más personal. Núria Esquerra (2008) productora del filme Unas fotos en la ciudad de Sylvia y de la videoinstalación Las mujeres que no conocemos presentada en la Biennale de Arte de Venecia 2007, escribe acerca de su colaboración con el cineasta en el montaje de la película:

El montaje ayudó a Guerin a ordenar sus ideas, ya que él piensa en imágenes y sonidos. De hecho, me parece que nunca ha escrito un guión estrictamente con palabras. En un principio, por tanto, esos montajes solo debían ser el germen de un guión o un borrador, unas notas preparatorias de ese film rodado en cine y con actores, que luego ha sido En la ciudad de Sylvia (...) Se trata de un procedimiento que, en 


\section{BRAC - Barcelona Research Art Creation, 2(2)}

principio, debería ser arcaico en el cine, sucesión de imágenes fijas, pero que está apenas explorado. El ritmo no está creado por el movimiento del plano o de los elementos dentro del encuadre, sino por la duración del instante detenido y sus relaciones con las otras imágenes fijas. El montaje se convierte en algo mucho más esencial. (p. 42)

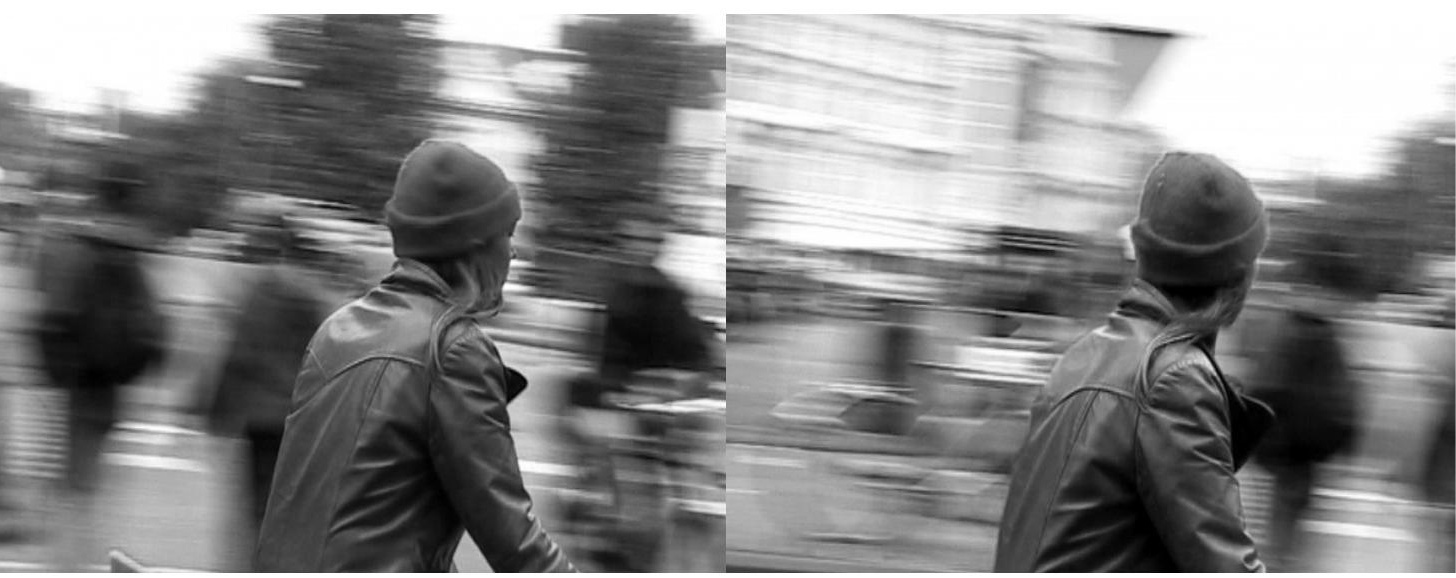

Figuras 1,2. Fotogramas de Unas fotos en la ciudad de Sylvia (J.L Guerín. 2007). Cortesía del autor. (C)

Unas fotos en la ciudad de Sylvia (figuras 1,2) es un ensayo fílmico, mudo y en blanco y negro, compuesto por una sucesión de fotografías, que son guiadas por relatos que orientan al espectador sobre su sentido, una recolección de textos y bocetos visuales, estructurados posteriormente en el montaje. Atípica obra del director si la comparamos con sus filmes más ficcionados. No obstante es una obra coherente dentro de la línea de Guest o de sus instalaciones de video. Aunque pueda leerse como el esbozo previo a La ciudad de Sylvia (2007), el estilo, la narrativa, el medio y la herramienta, actúan de puente entre sus películas y el lenguaje de sus exposiciones. En esta ocasión, la balanza se inclina hacia la experimentación con el montaje de imágenes captadas.

La película sitúa al espectador ante el proceso en bruto, desvelando la devoción por entrar en la intimidad de lo real y captar un instante de naturalidad. Utiliza el silencio, la consecución de imágenes y las intenciones ocultas, para conducir una narración incierta y seductora. Una serie de fotos fijas que son por sí mismas esbozos gestuales, que buscan una mirada sincera. 


\section{Martínez Villegas - Guerin: Descubriendo una sintaxis posible}

El cineasta nos invita así a entrar en la intimidad de su atelier, en su personal proceso creativo, obteniendo a cambio fuentes de futuras transformaciones. En las imágenes que conforman el film se encuentran las semillas, que posteriormente expande por proyección, en las dos instalaciones que realiza, ideadas para espacios expositivos.

Si relacionamos el conjunto de la obra cinematográfica de Guerin con su incursión en el arte contemporáneo, encontramos que Unas fotos... es una obra potencialmente muy importante del autor, ya que actúa como nexo de la expresión formal en sus instalaciones.

Entre el montaje del cine y el montaje en la instalación multipantalla existen grandes diferencias y a su vez estrechos vínculos de lenguaje. Tarkovski (1988) definió el montaje como una de las más importantes fases de la creación audiovisual; "es la relación del director con su idea, siendo la expresión de la forma definitiva de ver el mundo del director", relacionándolo con los vínculos que se establecen entre los elementos y con el sentido del tempo: "Su coordinación origina un cuadro rítmico único, una innovación orgánica creada por la sensibilidad temporal de su autor." (p. 148)

La lógica interna de la narrativa depende de su lenguaje interior, de la relación de las diferentes imágenes en movimiento. Este punto es común entre el cine, el videoarte o la instalación audiovisual, cada una de las áreas con sus particularidades. La primera exploración de Guerin en el espacio del arte contemporáneo, la exposición Las mujeres que no conocemos, se basó en una instalación multipantalla para el Pabellón de España en la 52a Bienal de Venecia de 2007, posteriormente expuesta en el CCCB (Centro de Cultura Contemporánea de Barcelona) en 2008.

La muestra fue la tercera parte de la línea temática desarrollada en el mismo año, que comenzó con Unas fotos en la ciudad de Sylvia (figuras 3, 4, 5, 6), seguida por En la ciudad de Sylvia (figuras 7, 8, 9, 10). La instalación fotosecuencial para la Bienal de Venecia, propuso un montaje diferente incluyendo el mismo material (figuras 11, 12, 13, 14, 15, 16, 17, 18), generando una construcción híbrida en el espacio dado; la fotografía en forma de proyección, planteaba al espectador una trama compleja, un recorrido por el diálogo que conformaban sus diferentes partes.

En el tipo de instalación que el cineasta plantea para las salas de arte, se suma el factor espacio y su relación con la imagen. La narrativa no lineal, expresada con una sola pantalla en el montaje cinematográfico y en su exposición natural, la sala de cine, es posibilitada en la instalación audiovisual de forma física, aplicando la trama a la experiencia del espectador paseante. 



Figuras 3, 4, 5, 6. (Izquierda) Fotogramas de Unas fotos en la ciudad de Sylvia (J.L Guerín. 2007). Cortesía del autor. (C)

Figuras 7, 8, 9, 10. (Derecha) Fotogramas de En la ciudad de Sylvia (J.L Guerín. 2007). Cortesía del autor. (C) 
180 Martínez Villegas - Guerin: Descubriendo una sintaxis posible

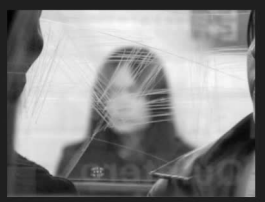

La imagen retenida
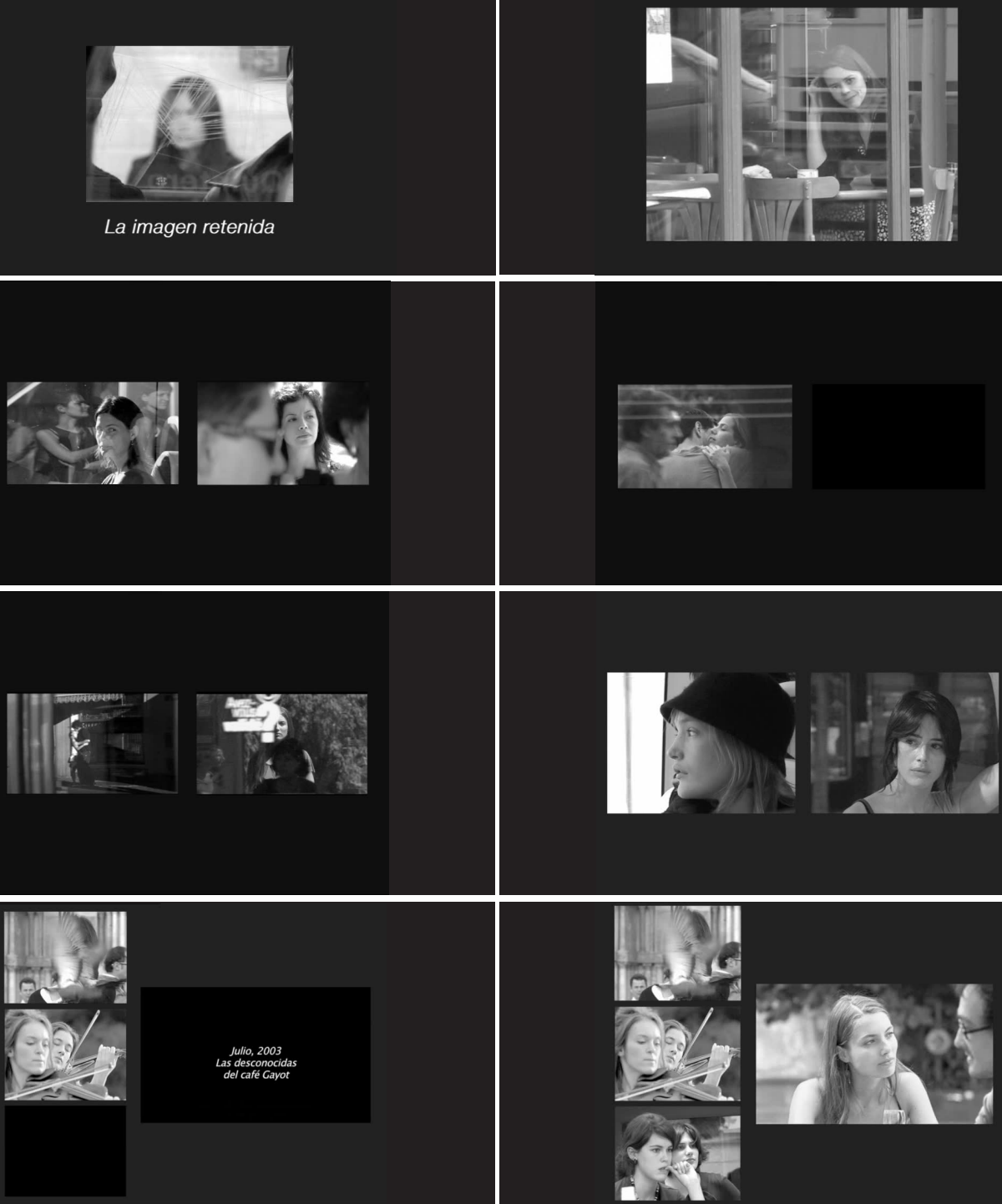

Figuras 11, 12, 13, 14, 15, 16, 17, 18. Montaje análogo (aproximación) de la Instalación Las mujeres que no conocemos. Filme en 24 cuadros. Pabellón de España 52a Bienal de Venecia 2007. (J.L Guerín. 2007). Cortesía del autor. (C) 


\section{Otra sintaxis posible}

Guerin se interesa por otras lecturas de su trabajo, que le permiten indagar en soluciones alternativas a la industria del cine para su imagen poética: “(...) voy descubriendo o pensando en una sintaxis posible, siempre con el propósito de utilizar estos espacios para explorar aquello que sé que en cine no podría, no me dejarían." 3

Sus historias abiertas adquieren un sentido diferente en la sala de arte. La bidimensionalidad de la pantalla da paso a un tipo de propuesta, que se acerca a las prácticas de video-artistas, que utilizan material cinematográfico propio o ajeno en sus obras. $\mathrm{O}$ a cineastas que no cómodos con la narrativa habitual del cine, desarrollan y exponen sus trabajos en el ámbito del arte contemporáneo, sirviéndose de un lenguaje que refuerza formalmente un tipo de relato complejo. El medio ayuda a conformar un tejido de solapamientos, estructurando fragmentos para encontrar la impresión de unidad, priorizando esta atmósfera, más cercana a la percepción humana y a la verdad del proceso artístico -que nunca es lineal- a una rigurosa lectura del guion.

Algunos autores que bien puntualmente o en exclusiva, operan por necesidad creativa en estos espacios de confluencia, realizan en sus procesos dos versiones de un mismo proyecto, pensadas para una doble salida; la sala de arte y el circuito cinematográfico. Es el caso de la artista y filmmaker ElijaLisa Ahtila (Finlandia, 1959) que respondiendo a las cuestiones de Doug Aitken declara:

[...] I make a work with moving images, I usually do both a film version and an installation version. The film version is distributed through festivals and on television, and the installation through galleries and museums. But if I think about my approach to the medium of the moving image itself, it's more as an artist. The important thing for me is to express myself through the medium. Only when I have to, do I think about the differences between the two fields, like when I try to get financing from the film world. It's then that I often realize how different my approach is. It's not always easy to find a common language. But fortunately there are people out there who are interested in the new developments going on in film narration $[\ldots]^{4}$ 


\section{Martínez Villegas - Guerin: Descubriendo una sintaxis posible}

Especialmente relevante es la aportación de Doug Aitken (California, 1968), video-artista con gran reconocimiento internacional en la actualidad, con su libro-manifiesto, compuesto por 26 entrevistas; Broken Screen. Expanding the Image Breaking the Narrative (Aitken, 2006). En su ensayo, Aitken analiza lo que ejerce en su carrera; la fragmentación de la narrativa en el cine, el videoarte y la instalación, recogiendo la opinión de cineastas y artistas, que tienen como factor común la deliberada no linealidad de sus obras audiovisuales. Robert Altman, Claire Denis, Bruce Conner, Gary Hill, entre otros, a través de conversaciones informales, desgranan las ideas, intenciones y necesidades de proceso, que hay detrás de la denominada expansión de la imagen.

En una aproximación a la contextualización de esta compleja práctica interdisciplinar, hay que nombrar al crítico Gene Youngblood (New York, 1942), que escribió uno de los primeros estudios de la ruptura de la narrativa fílmica convencional, acuñando el término Expanded Cinema (Youngblood, 1970), anticipando el potencial del medio, imbricándolo a la evolución de las nuevas tecnologías, y reclamando la necesidad de una nueva forma de cine para cambiar la percepción y la conciencia del espectador. Youngblood imbuido en el contexto de la época, atribuía al Cine Expandido un alcance redentor: "[...] La conclusión es que el arte y la tecnología del cine expandido suponen el principio de la vida creativa para toda la humanidad y, por lo tanto, una solución al llamado problema del tiempo libre." 5

Con cierta perspectiva, la artista e investigadora Esperanza Collado (2011) en su ensayo Paracinema. La desmaterialización del cine en las prácticas artísticas, emplea el término Paracinema, para definir el movimiento de aquellos autores, que han expresado aspectos propios del cine a través de otros medios. Según la autora, esta práctica no implica tanto la fractura del cine, sino su evolución hacia otras formas del arte. Se desmarca del término Cine expandido desarrollado por Youngblood diciendo:

Paracinema, en oposición al cine expandido, es la realización de la idea de cine a un nivel conceptual, experiencial y artístico. Se trata, en cualquier caso, de generar una experiencia cinemática desconectada, entera o parcialmente, de su aparato tradicional. (Contraportada)

En este sentido, a modo de ejemplo, son destacables los últimos trabajos del cineasta Peter Greenaway, muy vinculado con el arte desde temprana edad, formado como pintor, e interesado en reinventar el lenguaje cinematográfico 
y las posibilidades de la percepción de la imagen en movimiento. En 2009 y dentro del proyecto de gran envergadura Nine Classic Paintings, en el que imagina los procesos de creación y reformula a su manera, los planteamientos pictóricos de Velázquez, Caravaggio, Rembrandt, Rubens entre otros, presentó la multi-proyección The Wedding at Cana, inspirándose en el lienzo de El Veronés, Las bodas de Caná. La instalación se presentó por primera vez en el refectorio de San Giorgio de Venecia, espacio para el que fue creado originalmente el cuadro.

En un plano teórico, Alfonso Puyal (2012) en el artículo Cineastas en el museo, distingue hasta nueve formas de inclusión del cine en el ámbito expositivo: Introducción de películas en el museo; exposiciones que enfrentan la imagen en movimiento con la pintura; exposiciones divulgativas dedicadas a directores de cine; colectivas temáticas dedicadas a los dispositivos cinematográficos; apropiación del cine en el videoarte; trabajos cinematográficos hechos por artistas; obra plástica hecha por realizadores; correspondencias filmicas entre directores, y por último, cine de autor que realiza instalaciones por encargo del museo (pp. 104-119).

La segunda exposición de Guerin La dama de Corinto. Un esbozo cinematográfico (2011) (encargo al cineasta del Museo Esteban Vicente de Segovia), al igual que la primera, se sitúa en esa última definición que plantea Puyal.

En esta instalación el director pone en relación el ejercicio del cine con el origen de la pintura, tomando los textos de Plinio el Viejo en su Historia Natural. Guerin impulsa el planteamiento visual y conceptual, incidiendo en la confluencia entre la cinematografía y las artes plásticas. Y lo hace desde una imagen con un profundo significado convergente: una mujer, que ante la partida de su amado, decide trazar el contorno de su sombra en la pared, proyectada por la luz de una vela. La pintora originaria trabaja a partir del fenómeno de la proyección y no de la observación del modelo. En este mito originario, basa Guerin la confraternización entre la pintura y el cine, reforzando un argumento que ya formuló cuando fue invitado a la Bienal de Venecia, declarando sentirse legítimo heredero de la pintura, un arte extinto según el cineasta. La pieza principal de La dama de Corinto constaba del mediometraje Dos cartas a Ana, de 25 minutos y tres salas más que analizaban visualmente el concepto base, dividiéndolo en un total de 24 pantallas y proyecciones. La muestra contenía la dualidad entre imagen lírica y documental, con transiciones textuales que ilustraban la elaboración del mito originario al modo del cine mudo. Su visión cinematográfica se centraba 


\section{Martínez Villegas - Guerin: Descubriendo una sintaxis posible}

en generar el relato por secuenciación de pantallas, indagando en la dialéctica de la proyección, renovando los significados de sus piezas más intimistas, poniendo en relación la imagen y la configuración arquitectónica del espacio dado.

Jesús Martínez Clarà (2011) afirmaba al respecto de las imágenes contenidas en la exposición: "Las imágenes mudas de Guerin no quieren ser un instrumento al servicio de la narratividad, sino un valor por sí mismas, y eso exige del espectador máxima concentración en los detalles, atención casi litúrgica [...]” (p. 5). La cohesión y el interés de la trama que subyacía en la instalación dependía, al igual que en sus films, de las relaciones sutiles implícitas entre sus esbozos poéticos, en mayor medida de lo que los textos que actuaban de guía, trataban de aclarar.

Dentro de los proyectos curatoriales de cine expositivo, Guerin fue invitado a participar en la exposición colectiva Todas las cartas. Correspondencias filmicas, que tuvo lugar en el CCCB de Barcelona, desde octubre de 2011 hasta febrero de 2012, presentada un mes antes en la Casa Encendida de Madrid, teniendo su equivalente francés en el Centre Pompidou de Paris: Jonas Mekas / José Luis Guerin: Cinéastes en correspondance, Installation, en diciembre de 2012. La muestra, reunió varios intercambios fílmicos, compuestos por parejas de cineastas internacionales, como Isaki Lacuesta y Naomi Kawase; Albert Serra y Lisandro Alonso; Jaime Rosales y Wang Bing; Fernando Eimbcke y Yo Song Kim entre otros, siendo las cartas filmadas el tema argumental del proyecto. Los cineastas proponían bocetos cinematográficos, que evolucionaba el realizador receptor, partiendo del final que planteaba el autor encargado de arrancar la propuesta.

José Luis Guerin mantuvo su particular correspondencia con el poeta y video-artista lituano-norteamericano Jonas Mekas, recuperando en el arranque de la misiva su encuentro en Nueva York recogido en Guest. El cuidado blanco y negro del director catalán dialogaba con la imagen heterodoxa, entre lo familiar y lo amateur de Mekas. Un diálogo emocionalmente cautivador y formalmente dispar, entre dos autores que comparten el gusto por utilizar la cámara, como una parte de la memoria que atrapa momentos especiales, pero con diferentes métodos de creación, dos formas de entender el proceso. La imagen espontanea, diáfana de Mekas revela despreocupación por el montaje y pasión por la pulsión de grabarlo todo, haciendo de su actividad voayerística un modo de estar en el mundo, mirando la vida a través del objetivo. En su correspondencia, ambos dialogan sobre los hallazgos en las imágenes grabadas, la memoria y los procesos de creación. En este proyecto, Guerin 
contrasta la vertiente más autónoma de su modus operandi, con la actividad diaria de Mekas, uno de los artistas más respetados del cine experimental. El trabajo de Guerin contenía una refinada interpretación del encuadre, y el natural interés del cineasta por la coherencia de un montaje fragmentado. Es precisamente el montaje como agente estructural de los planos recolectados, uno de los argumentos centrales que comparten en su intercambio fílmico los dos autores; Guerin visita la añeja editing room de Mekas y responde, mostrando un plano en el que aparece su ordenador personal con el programa de edición de video, recalcando la importancia que la edición adquiere en un tipo de trabajo autónomo, en el que la imagen poética predomina sobre el argumento.

Fernando Canet (2013) orienta el proceso cinematográfico de Guerin, en la composición resultante de la tensión entre el azar y lo controlado, siendo "en la sala de montaje donde el material filmado se transfigura definitivamente en discurso, donde ese material resultado de llevar a la práctica la formulación cinemática I react to life, de Mekas [...] es finalmente ordenado dotándolo de sentido." (pp. 145-159).

El montaje aplicado ala instalación multi-proyección de sus dos exposiciones, exigía al cineasta además, enfrentarse al espacio, como factor determinante del relato, que proponían las diferentes proyecciones de fotografías o imágenes en movimiento. Los esbozos cinematográficos tomaban aquí entidad formal de piezas autónomas, siendo prioritario el diálogo y el acuerdo de su imagen poética; consigo misma por su expansión, seriación y relación entre sí, y con su tratamiento como objeto independiente modulable, y sobre todo con el espacio que las contiene y las vincula, logrando o no la percepción de un todo relacionado, complejo y rico, en la vivencia del espectador.

Atendiendo de nuevo al análisis que realiza Esperanza Collado (2011) del fenómeno de la expansión de la imagen cinematográfica, Guerin literalmente separa su cine del montaje habitual y su medio tradicional, lo deconstruye y lo recicla, encontrando una ubicación nueva con potencial capaz de multiplicar sus significados.

[...] la deconstrucción del cine y, en última instancia, su destrucción. El medio, sin embargo, no llega a destruirse a sí mismo como tal, sino que negocia su materialidad fenomenológica con las otras artes, formando un vínculo con ellas que las transforma para siempre. (p. 20) 
Rafael R. Tranche (2012) deja una cuestión en el aire con respecto a esta negociación; "[...] ambos discursos, ambos medios y sus ámbitos de contemplación parecen necesitarse mutuamente, están condenados a entenderse; la cuestión radica en dirimir en qué punto ha de producirse la intersección o la simbiosis" (p. 77).

Guerin no es una excepción como cineasta que mantiene una relación con el arte contemporáneo. Realizadores actuales como es el caso de Albert Serra (Girona, 1975), fue invitado para la $13^{\mathrm{a}}$ edición de la dOCUMENTA de Kassel, presentando Els tres porquets (2012), un retrato contemporáneo de Alemania, a través de los textos de tres personajes antagónicos de su historia reciente: Goethe, Hitler y Fassbinder, una película de 101 horas de duración, que se realizó en dos fases durante el evento, llegando al extremo de simultanear su montaje y su visionado. El Centre Pompidou de París ha acogido con la exposición La Carte Blanche la totalidad de la obra de Serra, durante los meses de abril y mayo de 2014, derivando la muestra de una de las Correspondencias filmicas del CCCB, entre Serra y el cineasta argentino Lisandro Alonso. Otro director incluido en esta exposición, Isaki Lacuesta, nacido en el mismo año y mismo lugar que su coetáneo Serra, es autor del documental El cuaderno de barro (2011) y del premiado largometraje Los pasos dobles (2011), ambos en colaboración con el pintor Miquel Barceló. Anteriormente se adentró en el espacio de la instalación, presentando entre otras intervenciones, De cos present (2012), instalación para siete pantallas, dentro del proyecto Arts del moviment, del Centre d'Arts Santa Mònica de Barcelona.

El Museu d'Art Contemporani de Barcelona (MACBA) en 2012, realizó la exposición Series militares sobre la obra del cineasta Aleksandr Sokurov (Podorvikha, Siberia, 1951), autor de la aclamada El arca rusa (2002) y Fausto (2011). Por su parte el MOMA de Nueva York en 2007, dedicó una retrospectiva a la obra del director Pere Portabella proyectando su largometraje Die Stille vor Bach (2007). La sensible y visualmente deslumbrante película de José María de Orbe, Aita (2010) fue también programada dentro del Documentary Fortnight: MoMA's Festival Nonfiction Film en 2012, y un año antes en la Tate Modern de Londres.

Se podrían nombrar un buen número de cineastas en la actualidad, que son atraídos por los museos. A todos les une una mirada particular, una forma distintiva de entender la imagen fílmica, el sentido del silencio y del tiempo. Obras que por su configuración estética y temporal, pueden funcionar con cierta independencia. 
Un apreciable proyecto comisarial que mostraba la mirada del videoarte hacia el cine, fue El efecto del cine. Ilusión, realidad e imagen en movimiento. Sueño-Realismo, CaixaForum Barcelona-Madrid (2011), en el que se exponían las obras de video-artistas que en su práctica, establecían espacios de encuentro con la cinematografía. El proyecto analizaba el cine como fenómeno de la cultura visual, dando coherencia temática a las dispares aportaciones, profundizando en conceptos como la representación del sueño y los estados oníricos, las realidades subconscientes y sus estados de percepción. Las dos exposiciones colectivas contaron con la particular visión cinematográfica de relevantes artistas como Julian Rosefeldt, Andy Warhol, Douglas Gordon, Bruce Conner, Rodney Graham, Christoph Girardet, entre otros.

Los video-artistas que se sitúan en espacios de confluencia con la cinematografía, tratan la materia fílmica como un componente esencial dentro del tejido del proceso. Es el caso de aquellos que elaboran su propia imagen cinematográfica -véase la obra de artistas como Mattew Barney (California, 1967) o Shirin Neshat (Irán, 1957)- o los que se apropian de material icónico - es el caso de notables obras de Nicolás Provost (Bélgica, 1969) o Douglas Gordon (Escocia, 1966)-. Cuando esta heterodoxa disciplina, se mezcla con el factor espacio -significativo el trabajo de la artista Pipilotti Rist (Suiza, 1962) o el propio Doug Aitken-. O bien se proyecta sobre objeto entrando en el ámbito escultórico - Win Geleynse (Holanda, 1947) o Tony Oursler (USA, 1957)-, la imagen en movimiento pasa a ser un factor del conjunto que elabora el discurso, generando una trama que posibilita el recorrido y la experiencia perceptiva del espectador.

El video-artista Isaac Julien, (Londres, 1960) estudió pintura y cine en St Martin's School of Art. En la actualidad, su trabajo es uno de los más interesantes exponentes, del comportamiento de la imagen en movimiento en la sala de arte. En su última instalación Playtime (Victoria Miro Gallery, Londres, febrero de 2014), siete proyecciones a la vez, ofrecen un visionado múltiple de tres narraciones interconectadas, rodadas en Londres, Reykjavik y Dubai. En las escenas se pueden encontrar diferentes miradas simultáneas de un mismo fenómeno. El ritmo del filme o de los filmes contenidos, compuestos de relatos cruzados por el concepto subyacente, se ve favorecido por su extensión formal. El tema de fondo, la globalización del capital y de las personas, y la permanente sensación de movilidad, se refuerza formalmente por la diversidad de puntos de vista de la multi-pantalla.

La utilización durante el proceso de creación, del solapamiento de capas conceptuales y formales, como son los significados contenidos en la imagen 


\section{Martínez Villegas - Guerin: Descubriendo una sintaxis posible}

en movimiento en su relación entre sí, y con el espacio u objeto sobre los que se proyecta, forma parte del trabajo habitual de los autores que operan en estos terrenos de encuentro. Trabajos que son en último término, pensados y adaptados en ocasiones para espacios exteriores, y en general para el cubo blanco de la sala de arte.

Una de los aspectos que provoca la fricción en los encuentros confluyentes entre el cine y el arte, podría ser esta condición; el empleo del espacio expositivo, es decir, el conocimiento de la relación entre las sinergias del contenido y el contenedor. Este es un campo extensamente estudiado por el arte contemporáneo, al que los cineastas se enfrentan dentro del desarrollo del film, pero no en la exhibición de su trabajo. Una parcela con sus reglas y lenguaje propios, como todos los ámbitos de la expresión artística, capaz de multiplicar y potenciar el valor de la imagen poética, pero también de diseminarla y restarle su capacidad de síntesis o unidad.

En la entrevista con el director, contenida en el presente artículo, Guerin opina sobre esta fricción:

[...] hay un gran analfabetismo entre unos y otros, están en compartimentos estancos, no se conocen [...] Muchos artistas sienten desdén hacia el cine, como si no fuera algo serio, y a veces pecan de una ingenuidad extraordinaria porque hay cosas que el cine ha resuelto hace muchísimo tiempo. Y también a la inversa, es decir, hay cineastas que te miran muy raro por haber intervenido en el espacio del arte [...] Son espacios que se comunican poco, es muy raro y muy anómalo. ${ }^{6}$

\section{Conclusiones}

Guerin ensaya con la multi-proyección en salas de arte, lo que dentro de la industria del cine le es inviable. Resulta esta práctica una vía propicia para presentar su manera de concebir la cinematografía, que por su particular configuración del tiempo, la imagen y el montaje, deviene en narrativas no lineales. Su experimentación en la instalación audiovisual, viene a ser otra forma de montaje, en la que formalmente la narrativa se rompe y a la vez se unifica en su percepción espacial, dando coherencia poética, visual y argumental a un conjunto de esbozos, creados expresamente para la exposición, o bien recuperados de material anterior. Gestos que en Guest, o -en forma de fotografías fijas-, en Unas fotos en la ciudad de Sylvia, son ordenados secuencialmente. 
Los caminos abiertos, planteados por el director en sus exposiciones; Las mujeres que no conocemos y La dama de Corinto, guardan una estrecha relación con sus películas más personales, posibilitando una doble salida a su imagen poética; en el terreno de la industria del cine y en el del arte contemporáneo. Este hecho le sitúa en el umbral de los espacios de hibridación, en el que se encuentran otros artistas en la actualidad, que fluctúan entre los dos ámbitos. Autores que encuentran en estas experiencias confluyentes un lugar coherente, para la expresión de una multiplicidad que compone un todo, más cercana a la manera en la que percibimos nuestro entorno que el relato lineal, implicando también una invitación al espectador, a participar en la complejidad e incertidumbre inherente al proceso de creación.

\section{Agradecimientos}

Este artículo se enmarca dentro del programa FPU (Formación del Profesorado Universitario) del Ministerio de Educación, Cultura y Deporte, desempeñado en la Facultad de Bellas Artes de la Universidad de Barcelona.

Especial agradecimiento a José Luis Guerin y Núria Esquerra por su amabilidad y disponibilidad.

\section{Notas}

${ }^{1}$ Diccionario de la lengua española (DRAE) 22. ${ }^{\text {a }}$ Edición, publicada en 2001

${ }^{2}$ Mekas, Jonas. Declaraciones contenidas en Guest, José Luis Guerin 2007.

${ }^{3}$ Guerin, J.L. Declaraciones tomadas de la entrevista contenida en el presente artículo. Barcelona 11 de Junio del 2012

${ }^{4}$ Entrevista de Doug Aitken a Elija-Lisa Ahtila, contenida en: Broken Screen. Conversations with Doug Aitken. Expanding the Image Breaking the Narrative. 2006 D.A.P./Art publishers. Nueva York. ISBN 1-933045-26-4. p. 18

${ }^{5}$ Youngblood, Gene. Cine Expandido. EDUNTREF. Buenos Aires, 2012. p. 59. Traducción de la edición Expanded Cinema. Editorial: EP Dutton. New York, 1970.

${ }^{6}$ Guerin, J.L. Declaraciones tomadas de la entrevista contenida en el presente artículo. Barcelona 11 de Junio del 2012

7 El director habla sobre la exposición Series militares de Aleksandr Sokurov (2012), en el Museu d'Art Contemporani de Barcelona (MACBA)

${ }^{8}$ Guerin se refiere al Jeonju Digital Project, dentro del festival de cine coreano Jeonju International Film Festival (2011)

${ }^{9}$ El cineasta menciona a André Bazin en ¿Qué es el cine? I. Ontología de la imagen fotográfica. p. 29: "[...] la fotografía no crea como el arte Ia eternidad, sino que embalsama el tiempo; se limita a sustraerlo a su propia corrupción. En esta perspectiva, el cine se nos muestra como la realización en el tiempo de la objetividad fotográfica." 
190 Martinez Villegas - Guerin: Descubriendo una sintaxis posible

\section{Referencias}

Aitken, D. (2006). Broken Screen. Conversations with Doug Aitken.

Expanding the Image Breaking the Narrative. Nueva York. D.A.P./Art publishers, 18.

Bachelard, G. (1975). La poética del espacio (2a ed.). México D.F. Fondo de Cultura Económica, 7, 8, 15

Bazin, A. (2001) ¿Qué es el cine? Madrid. Ediciones RIALP, 29.

Bresson, R. (1979). Notas sobre el cinematógrafo (2 $2^{\mathrm{a}}$ ed.). México D.F.

Ediciones Era S.A., 10.

Canet, F. (2013). La fricción entre lo azar y lo controlado en el cine de José

Luis Guerin. Archivos de la filmoteca 72, 145-159.

Collado Sánchez, E. (2012). Paracinema. La desmaterialización del cine

en las prácticas artísticas. Madrid. Trama editorial y Fundación Arte y

Derecho, contraportada, 20.

De Lucas, G. (2011, 30 de Marzo). Los ojos frente a la cámara. Cultural La vanguardia, p. 3.

Esquerra, N. (2008). A propósito del montaje de "Unas fotos en la ciudad de

Sylvia". Libreto contenido en la edición del DVD, 42.

Losilla, C. (2011). Donde ya no estamos. Cahiers du Cinéma España, $N^{o} 42$, 24, 25.

Martinez Clará, J. (2011, 30 Marzo). La dama de Corinto. Ut pictura kinesis. Cultural La vanguardia, p. 5.

Mayer, M. (2010). Le temps des fantômes. Approche de l'oeuvre cinématographique de José Luis Guerin. Tesis doctoral. (Traducción al castellano). Universitat Pompeu Fabra y Aix-Marseille Université, 409. Puyal, A. (2012). Cineastas en el museo: José Luis Guerin. Archivos de la Filmoteca 69, 104-119.

Tarkovski, A. (2008). Esculpir en el tiempo. Reflexiones sobre el arte, la estética y la poética del cine $\left(9^{\mathrm{a}}\right.$ ed.). Madrid. Ediciones RIALP, S.A., 148.

Tranche, R. (2012). De la pantalla al lienzo: Cine proyectado y cine expuesto. Archivos de la filmoteca 69, 74-77.

Youngblood, G. (2012). Cine Expandido. Buenos Aires. EDUNTREF, 59. Primera edición: Expanded Cinema (1970). New York: E. P. Dutton \& Co. 
Juan Martínez Villegas: Estudiante de doctorado y becario de Investigación FPU. Departamento de Escultura. Universidad de Barcelona.

Contact Address: Facultad de Bellas Artes. Universidad de Barcelona. Departamento de Escultura. c/ Pau Gargallo 4, 08028 Barcelona (España). E-mail address: juanmartinezvillegas@gmail.com

\section{Anexo}

\section{Entrevista a José Luis Guerin}

Plaza de Sant Pere, Barcelona, 11 de junio de 2012.

- JMV. Pregunta: En tu segunda instalación audiovisual, expusiste en el Museo Esteban Vicente de Segovia con "La dama de Corinto. Un esbozo cinematográfico", una videoinstalación o cine fraccionado, en la que proponías un espacio de confluencia a partir de imágenes en movimiento. ¿Empiezas a preocuparte por el espacio expositivo?

- JLG. Respuesta: Sí, es curioso porque el viento sopla donde quiere siempre, yo nunca había pensado si nadie me lo pide, entrar en el sector del arte, de la videoinstalación, incluso era bastante escéptico con estos territorios. La cuestión es que me lo han pedido más de una vez, y voy descubriendo o pensando en una sintaxis posible, siempre con el propósito de utilizar estos espacios para explorar aquello que sé que en cine no podría, no me dejarían.

La primera experiencia fue para el Pabellón de España en la Bienal de Arte de Venecia 2007 con Las mujeres que no conocemos. Lo que pensé es; voy a utilizar esto para experimentar mi propio medio, que es el cine, desde las nuevas posibilidades que te da el espacio expositivo. De entrada creo que el espectador de un espacio de arte es esencialmente un flâneur, un paseante. En la medida en que el espacio de los cines, cada vez más hostil en términos de exhibición pura, el museo tiene también esa función estrictamente cinematográfica de 


\section{Martínez Villegas - Guerin: Descubriendo una sintaxis posible}

mostrar aquello que no se ve, donde no llegan las salas de cine. En principio pensé que había que respetar la naturaleza de ese paseante, al que no le gusta detenerse porque frustra su expectativa de recorrer un espacio, por tanto pensé una forma de secuencialidad desglosada en el espacio, intentando que el movimiento esté más en el espectador que en las pantallas. Lo que me sale más natural es la imagen en términos de blanco y negro, y siempre he querido hacer una película muda. Atendiendo a los legados originarios del cine. Esos que en las salas de cine no puedes explorar, sin embargo en las otras salas tienes una posibilidad, que es esta paradoja de utilizar el arte del futuro para pensar tu pasado más remoto, en este caso la fotografía secuencial. Ésta es una tradición de Étienne Jules Marey y Eadweard Muybridge, una foto tras otra en blanco y negro muda y La Dama de Corinto que está más atrás todavía de la fotografía, antes, los pintores de la Escuela Helénica, cuyas pinturas han desaparecido. En la medida en que mi medio, el cine está en trance de desaparecer, tiene necesidad de ponerse en relación, de sentirse parte de una trama.

- JMV. Hablando de "La Dama de Corinto". Era interesante la metáfora de la silueta en la pared desde la proyección. Tú planteabas que el cine tiene una herencia de la pintura, sin embargo la sombra que le servía para dibujar la silueta de su amado, era un símil a lo que luego hacías en la sala fijando una proyección de luz. Esto también denota una relación con el espacio escultórico.

- JLG. Cuando este museo de pintura me invitó a hacer algo, yo pensé en ese mito originario, en el que se encuentran el origen de la pintura o el del cine, como origen mítico. Al precisar esa primera pintora una sombra desde una proyección, ahí está el cine. Por otro lado, está planteándose constantemente ese conflicto entre dimensiones espaciales, tal como tú lo planteas, el espacio de la pintura y el espacio de la escultura. Y esa tensión latente, secreta, es la que rige toda la trama de la exposición. De un lado es lo que lleva a fraternizar íntimamente pintura y cine, la condena o la cualidad de esa bidimensionalidad que nunca han aceptado ni uno ni otro medio, hasta la pintura moderna.

- JMV. Pero en el momento en el que haces una fragmentación de la narrativa estás renunciando de alguna forma a la bidimensionalidad.

- JLG. Efectivamente, estoy tensándola de distintas maneras, una con la arquitectura, la imagen plana cuestionada con saltos de pared, una imagen bidimensional y sin embargo violentada con la arquitectura, es algo que me gusta mucho, si me invitan más veces a museos pienso seguir jugando con ello. Y de otro lado con la relación en el espacio ante las pantallas. Había una 
sala en la que una muchacha contemplaba un cuadro y acababa volviéndose al espectador, mirando no a ti sino a lo que había detrás, que eran las otras proyecciones, y se creaba una relación de plano contra plano en el espacio. Es decir que abre otra relación entre las pantallas, no son sólo los planos que se suceden temporalmente sino cómo se relacionan en un espacio.

- JMV. Y ¿por qué piensas que un cineasta despierta interés en el mundo del arte contemporáneo?

- JLG. Según me dijo el comisario de Venecia, le gustaban mis películas, pero me llamó por una intervención mía en el 2006 creo, en la que me invitaron a hacer algo en las páginas interiores del cultural de La Vanguardia. Hice un juego con fotos, en la dirección con lo que llevaba haciendo con las fotos mudas de Unas fotos en la ciudad de Sylvia. Y ese juego le hizo pensar en que podía hacer algo más, fue una gran sorpresa. Creo que era únicamente por esto, a mi me gusta mucho la pintura, soy ferviente paseante de museos de pintura, pero no creo que tuviera noticia de esto.

- JMV. ¿No crees que de alguna forma tu cine tiende lazos, más o menos visibles con el arte?

- JLG. Pues será, me es difícil ponerme en su punto de vista pero sí, seguramente en algunas películas mías como Tren de sombras, hay más diálogo con la pintura.

- JMV. ¿Quédiferencias crees que hay entre el pensamiento cinematográfico y el pensamiento video-artístico?

- $J L G$. En España es muy notable, porque hay un gran analfabetismo entre unos y otros, están en compartimentos estancos, no se conocen, esto en Francia no es así. Muchos artistas sienten desdén hacia el cine, como si no fuera algo serio, y a veces pecan de una ingenuidad extraordinaria, porque hay cosas que el cine ha resuelto hace muchísimo tiempo. Y también a la inversa, es decir, hay cineastas que te miran muy raro por haber intervenido en el espacio del arte y les parece que eres un pijo (risas), por aceptar una invitación en ese otro espacio. Son espacios que se comunican poco, es muy anómalo. Diríamos que probablemente sería que el videasta buscaría su espejo no en el cine, sino en otras fuentes del arte contemporáneo esencialmente.

- JMV. Me refería a la mirada. ¿Esa mirada no crees que es común?

- JLG. Yo creo simplemente que tiene que ver con una conciencia de tus medios, y esa conciencia se hará visible en el modo de mirar, de encuadrar, de montar, como enunciador de una película. Pero es la conciencia de una cierta memoria y un diálogo con tus medios. Un diálogo que no tiene porqué manifestarse con pesados desarrollos teóricos, simplemente está en el modo 


\section{Martínez Villegas - Guerin: Descubriendo una sintaxis posible}

de encuadrar. Tienes una cierta idea de cine o no, lo ves en los trabajos si está presente. Es verdad que eventualmente aparecen, cineastas que no han visto mucho cine, que han recogido una sensibilidad muy especial de los signos de la modernidad de su medio. Tiene que ver con esto, no tiene nada que ver con las herramientas empleadas. Mi película Guest está hecha con una cámara pequeña. En ningún caso tiene que ver con la tecnología, la tecnología es un falso problema, se habla demasiado de tecnología, y lo que importan son las ideas.

- JMV. ¿No crees que en Guest hay varias piezas que se acercan a un lenguaje video-artístico y que podrían ser autónomas? Es decir, es un trabajo en el que hay un hilo, pero no hay un hilo muy evidente, es más bien sutil, $y$ dentro de ese mismo trabajo hay varias direcciones, hay una imagen muy poética, pero hay otra que es más... ¿de captación del mundo quizás? O de una visión del mundo.

- JLG. Pensaba en el libro de Marco Polo, una Descripción del mundo. Tú me dices.. como una pieza de videoarte... ¿eso que querría decir? Una cosa que de entrada me hace muy precavido con el videoarte es la dispersión, con esto he sido muy reticente. A mi me gusta mucho la concentración de la unidad, la pantalla, la oscuridad y casi nunca me he creído la retórica esa de la interactividad, por el hecho de que haya más pantallas es más interactivo, o que el espectador use botones para interactuar, no es verdad, es una falsa ilusión. Casi todas las instalaciones que juegan con la ilusión de la interactividad son sumamente alienantes, se ha hecho mucha retórica con esto, es muy frustrante. En el museo las piezas de videoarte y la instalación pueden tener distintas estrategias con el tiempo, tiempos aleatorios, captas unos segundos y puedes tener cierta idea de la propuesta en las imágenes, pero la mayoría de veces no es así, la mayoría tienen un continuum temporal de desarrollo y esto favorece la dispersión, tener ocupado al ojo, el mirar sin ver. Eso se da mucho en el diseño del espacio que podría ser muy próximo a lo publicitario. Esto me irrita mucho. No hace mucho fui al MACBA a ver unas películas de Sokurov. ${ }^{7}$

Estuve una hora y media, completamente solo, pero a lo largo del visionado iban asomando un minuto, medio minuto, tres minutos, al menos 50 personas. Habría que informar al espectador de cuál es el planteamiento temporal de los trabajos. Porque a veces es una película normal, es documentación. Están muy confusos los espectadores, como zombis en la oscuridad mirando a un lado y a otro, sin saber cómo relacionarse con lo que ven. Esto me angustia mucho. En la Dama de Corinto planteaba empezar con una proyección de casi media hora que daba unas bases y después loops brevísimos con cuadros a veces en 
movimiento pero que no implicara una intención, porque el espectador es muy perezoso. Seguramente lo es igual con los cuadros. Al no tener una dimensión temporal, la gente pasea frente a ellos pero probablemente la mayoría de espectadores no han visto nada, han paseado la mirada sobre la superficie de muchos cuadros sin haber visto nada. Pero bueno, la dimensión temporal de los audiovisuales evidencian ese contrasentido. El espectador la mayoría de casos no es un espectador, es un consumidor que mira sin ver.

- JMV. Hemos hablado del aspecto formal del video. Al hacer esta comparación con Guest, me refería a la poesía contenida en las imágenes, que luego se enlazan un a con otra pero siguen siendo independientes. Un pato en la Habana, o un reflejo bajo un canal en Venecia. Son pequeñas piezas que comparo con el videoarte, en el sentido contrario a la dispersión: el poder de la poética concentrado en una imagen muy esencial.

- $J L G$. Sí, tiene que ver mucho con la fotografía.

Yo intento en cada proyecto, en cada película, hacer algo completamente distinto, y utilizando una forma de producción muy específica. Siempre lo he hecho así, me gusta recordar que Flaherty, cuando hizo Nanook el esquimal, a quien acudió no fue a una productora de cine, sino a una compañía de pieles. No sabían nada de cine, por eso le dejaban libertad absoluta. Siempre ante las características de una nueva producción me pregunto qué puedo hacer con esa forma de producción, que no puedo hacer en otro espacio, es lo que me da singularidad intrínseca. En Tren de sombras la presencia de Pere Portabella como productor, me liberaba del servilismo del guión y me posibilitaba hacer una película de ficción pensada de otra manera. En En construcción lo que me daba la universidad era la posibilidad de trabajar con estudiantes, con los que podía estar conviviendo periodos muy largos en un espacio, algo que con técnicos veteranos hubiese sido imposible. Cada película es hija de una experiencia única y singular. Las de los museos igual, busco un objeto que sólo es posible en esa experiencia. En Guest me propuse este pacto, un año yendo a todas partes con la camarita, y sí es cierto que lo que me atraía como principio estético era esa idea de módulos independientes y ciertas rimas subterráneas que dan una composición global. Esto hace que no se puedan cambiar de orden. Pensaba con los módulos, que igual se podía hacer algo como en Rayuela de Cortázar, pero me parece que no, que es más aparente que real, o sea que si lo ves con calma hay muchas más leyes de progresión de las que parecen, aunque cada bloque efectivamente sea abierto.

- JLV. Encuentro que hay unas relaciones, que ya me dirás si estaban en ti, entre el funcionamiento de "Guest", "La Dama de Corinto" y "Unas fotos en 


\section{Martínez Villegas - Guerin: Descubriendo una sintaxis posible}

la ciudad de Sylvia”, creo que está todo interconectado.

- JLG. Ahora que lo dices, soy consciente de Las mujeres que no conocemos y Guest, que aunque sean cada una con sus materiales, pero sí que son de la misma naturaleza. Hay una cosa que lo une todo, tienes razón, que es la herramienta, la modestia de la herramienta y el hecho de que sean piezas pensadas como soliloquios. Eso quizá ha sido un cambio muy importante que me han dado las nuevas tecnologías, el hecho de que se difuminan las fronteras entre un trabajo y otro. En Los motivos de Berta e Innisfree, clausuraba una experiencia y pasaba un largo periodo de tiempo en el que empezaba algo completamente distinto. El hecho de tener las herramientas de trabajo en casa, trabajar con una pequeña cámara.

- JMV. ¿Editas en casa?

- JLG. Sí. El tener las herramientas en casa te da otra forma de pensar. Por libre que te sientas en una moviola o un laboratorio trabajando con otra persona, siempre tienes el sentimiento de que debes rentabilizar el tiempo, que no es un tiempo solo tuyo sino que hay otra persona, incluso un espacio que se ha de rentabilizar, esto cambia completamente, aunque no seas consciente cambia radicalmente el modo de pensar. Te levantas por la mañana, con el café te acercas a tu mesa de trabajo. Me lo he puesto en mi escritorio, en el espacio en el que escribo; y escribes imágenes. Captas una imagen, la introduces en la memoria de tu ordenador, la relacionas con otra imagen que ya tenías tiempo atrás, la guardas en una carpeta, no haces nada con ello. Meses después hay una tercera imagen que se pone en relación con eso. Es decir que sería exactamente el modo de pensar de un escritor, el hecho de tener un esbozo, guardar en una carpeta, poner en relación una idea con otra.

- JMV. O de un artista.

- JLG. Sí, según con que formas de arte.

Esa superación de unas barreras industriales que a veces me cuesta recordar si esa imagen estaba en las mujeres de La ciudad de Sylvia, o en Las mujeres que no conocemos o en Guest. Hay una interrelación, se hace más magmático todo. Es así, pero son los trabajos que he hecho solo, lo que yo llamo soliloquios, porque eres tú y tus circunstancias.

Yo siento mucho el deseo también de recuperar el trabajo en equipo, me gustaría que la siguiente película fuera de equipo, de envergadura, pero tengo esas dos opciones, el trabajo con equipo y el trabajo más de soliloquio, en cuyo caso, sí piensas en que hay una unidad final, que es tu pensamiento especulando con imágenes distintas.

- JMV. ¿Pero no crees que es muy distinta una cosa de la otra? 
- $J L G$. ¿El trabajo en equipo y el trabajo en solitario?

- JMV. Sí y el resultado incluso, el proceso y el resultado. O sea, "Guest", no tiene nada que ver con "En la ciudad de Sylvia".

- JLG. Pero "En la ciudad de Sylvia" sí tiene que ver con "Unas fotos en la ciudad de Sylvia".

- JMV. ¿Fue posterior no? "La ciudad de Sylvia" a "Unas fotos..."

- $J L G$. Sí. Aunque luego fantaseaba, a veces cuando estoy preocupado con el modo de vivir y tal, con hacer una versión de En la ciudad de Sylvia pero fotográfica, convertirla en una fotonovela (risas). Me hubiera gustado hacerlo, incluso a veces pienso, si me quedo sin dinero y me arruino, puedo hacer adaptaciones fotográficas de películas o reinventar las relaciones distintas con fotos de películas que ya he hecho.

- JMV. En "Unas fotos...", hay captación de verdad, sin embargo en "La ciudad de Sylvia" hay actores. Partiendo del principio que Bresson apunta en sus Notas sobre el Cinematógrafo (1979), sobre los modelos y los actores, son cosas totalmente opuestas ¿no?

- JLG. Bueno, a mi me gusta confundirlas, en Unas fotos... capté una chica que doblaba una esquina, que tenía guardada, fue una de las primeras capturas instantáneas, luego hay amigas mías también que obedecen mis instrucciones. Es decir que es una construcción, es un artificio. El hecho de que utilice la primera persona del singular en los textos confunde a muchos, como si fuera una experiencia, un diario de verdad mío.

- JMV. Lo había llevado por ahí, pero no por los textos sino por las imágenes.

- JLG. En En La ciudad de Sylvia, hay mucha captura real también. En la secuencia de la terraza que para mi es la más importante, la mayoría de personas no son actores. Aquí les planteo una situación, un motivo de diálogo, les cuento una historia horrible, les creo la situación, espero y me gusta ver qué pasa, como cambian sus expresiones, es decir que cuando hago una ficción voy a buscar pactos con lo aleatorio, con lo accidental que me transfiere, y cuando la materia prima es azarosa por naturaleza en la realidad, busco procedimientos para componer, para estructurar, estilizar esa materia prima.

-JMV. Y hablando de Bresson. ¿Anhelas algo que te gustaría aprehender para tu trabajo de la obra de Bresson?

-JLG. No. Está bien que sea fundamental para mi educación como espectador, para mi crecimiento sentimental incluso, lo que me ha revelado su escritura, para una sensibilidad que no tendría si no hubiese visto sus películas, pero es un sedimento. Ser como Bresson sin ser él, te lleva seguro al fracaso. 


\section{Martínez Villegas - Guerin: Descubriendo una sintaxis posible}

-JMV. Seguro. Me refiero a algún aspecto que te gustaría tener... esto me arrebata y me encantaría que algún día me saliera propio... Si es que hay algo.

-JLG. ...Su independencia como cineasta. Ser como una roca frente al oleaje del cine, manteniéndose como un islote. Eso sí que me gustaría, pero es más de índole práctica. Y yo no lo hago en absoluto.

-JMV. Bueno, creo que un poco sí...

-JLG. Sí, algo sí. Pero cuando voy a algún programa de televisión o de radio, pienso que él nunca hubiese ido (risas). Yo le conocí, ¿lo sabías?

-JMV. Sí, te lo oi en una entrevista.

-JLG. ¿En el bonus de Lancelot du Lac?

-JMV. Sí, eso es. ¿Y qué tal la experiencia?

-JLG. Yo era muy joven y hablaba muy mal francés, decía lo que entendía. Tenía ese lado muy privado. No daba entrevistas a periodistas pero si tenía la garantía de que no eras periodista y te gustaba mucho su cine, le alagaba. En el bonus, contaba que como espectador, el final de Lancelot du Lac, en el que con estrépito, caía la última armadura, era como un Haiku, similar a cuando los monjes budistas hacían ver la iluminación desde algo muy simple, como el croar de una rana.

Siempre pienso que mi despertar en el cine, mi estadio de madurez, tal vez fue esa armadura cayendo. Por eso te digo que no se trata tanto de copiar una estrategia, sino que la deuda que tengo con él, es el cine, no los procedimientos o los trucos.

-JMV. Él manejaba muy bien el tiempo, los bloques de tiempo ¿verdad?

-JLG. El tiempo y el espacio; el cine. ¿Qué es el cine sino trozos de tiempo y espacio? La pausa bressoniana. Fíjate qué tiempos más distintos entre $U n$ condenado a muerte se ha escapado, Pickpocket y el tempo lírico de Al Azar, Baltasar, que es la única película que no tiene un tempo tan conciso, tan seco, es más rápida.

- JMV. Hablando de los hallazgos en arte. ¿Grabas a diario?

- JLG. No

- JMV. ¿Con qué frecuencia sacas la cámara y sales a grabar sin más?

- JLG. Cuando me he sometido a experiencias como en Unas fotos... o en Guest sí, me someto a la disciplina de ir con la cámara a todas partes. Pero después de estas experiencias es muy importante mantener una higiene mental. Esto ha terminado, se ha clausurado, salgo a pasear sin cámara. Es importante ver sin mediación de la cámara, es una forma de alienación terrible estar encuadrándolo todo. 
- JMV. Es decir no grabas por grabar, lo haces dentro de un proyecto

- JLG. Es sorprendente porque muchas veces has grabado algo sin saber porqué. Y sólo se revela mucho tiempo después, el motivo por el que has capturado una imagen. Tengo un proyecto, no sé si has oído hablar, que no se puede pasar de momento, que se llama Recuerdos de una mañana. Es una película de 40 minutos que la ha producido un festival de cine en Corea, que cada año produce un tríptico de tres partes y este año, produjo una pieza a JeanMarie Straub, otra a Claire Denis y otra a mí. ${ }^{8}$ La mía se llama Recuerdos de una mañana, y es un retazo de mi calle, pero a la sombra de un acontecimiento dramático, porque el vecino que vivía enfrente de mi casa, un violinista, todos los días ensayaba el violín en el balcón, se arrojó desnudo por la ventana y creó una conmoción. A mí me impresionó mucho que ese violinista acababa de traducir Las penas del joven Werther, de Goethe, es un libro para mí de cabecera, y es un libro que estuvo censurado en muchos países por apología del suicidio. Bueno, es un trabajo sobre esto, ese trabajo lo hice porque había hecho un plano del vecino tocando el violín en la misma ventana por la que se arrojó tiempo después. Yo no sabía que esa imagen... cuando volví de Guest porque estaba viajando cuando aconteció esto, tuve la necesidad de recuperar esa imagen.

- JMV. ¿Es premonitorio no?

- JLG. También Unas fotos en la ciudad de Sylvia no sabía por qué las hacía, tiempo después encontré el motivo, y dije, vale, era por eso. Está ese lado muy instintivo, y parece que a veces obedeces a este instinto. Es verdad que eso nos hace más parecidos a los artistas, porque antes de que existieran estas herramientas eso no podía ser así, no podías atender a tus intuiciones con esa sinceridad... debo tomar esa imagen.

- JMV. Con esa inmediatez

- JLG. Claro, tienes que estar muy seguro de las cosas para hacer imágenes en cine. Hay un gran presupuesto y un número de persona, no cabe ese grado de permeabilidad.

- JMV. ¿Vas a continuar por la línea iniciada en "Guest”? ¿crees que te ha abierto un camino o es un proyecto aislado?

- JLG. No lo sé, te diría que si no hubiese sido tan terrible la indiferencia absoluta con Guest, el que haya sido estrenada en la clandestinidad. Si esto hubiese sido de otra forma seguramente habría abierto un camino. Me hubiera gustado que se hubiese estrenado de una manera más normal y se hubiese podido visibilizar de otro modo.

- JMV. ¿Crees que tiene que ver el uso del blanco y negro? 
- JLG. No, no. Creo que fue debido verdaderamente a la indiferencia de la productora. Es muy importante crear una imagen de la película, y no lo hicieron, ni un anuncio del tamaño de un sello, un festival en el que no amortizaron la experiencia de ir a Venecia. Pensaron que era una película de festivales o de gente pobre, no lo sé. En construcción podría haber tenido la misma suerte que Guest. Yo estoy dolido con esto, y soy sensible también a esto, no soy impermeable ante la indiferencia.

- JMV. A como se recoge tu trabajo

- JLG. Sí. A veces he estado tentado de hacerlo, como los cineastas experimentales: yo a lo mío, y sin embargo sigo valorando el hecho de los estrenos los viernes, que me cuesta muchísimo, las entrevistas y formar parte del dispositivo mediático, pero creo que es un foco de resistencia que debo atender y temo también la actitud acomodaticia del que se aísla de todo esto...: "yo soy un artista y hago mi arte sin tener en cuenta nada más".

Si quiero concederme la posibilidad de hacer Unas fotos en la ciudad de Sylvia, lo hago con mis herramientas pero manteniendo un cierto diálogo con la sociedad. Esto me angustia, que el cine cuente tan poco ahora en la sociedad. Cuando yo descubrí el cine, era algo muy importante. Ahora es el fútbol, ahora las adolescentes en sus habitaciones no tienen carteles de actores ni de cantantes rock, sino de futbolistas, es el gran tótem sagrado de nuestra sociedad.

-JMV. ¿Crees que el cine tiene un sentido nostálgico de la vida? Es decir, la posibilidad de ver una película reiteradamente es responsabilidad del espectador, ¿pero de alguna forma el cineasta lo propicia?

-JLG. No creo que esté intrínsecamente en el cine. O sí, que diablos, en la medida en que rescata el tiempo que ha pasado, y es muy fácil que se desate la nostalgia. Sí, yo siempre tengo muy presente a Andrè Bazin, con su fórmula de "embalsamar el tiempo" (Bazin, 2001), el cine como el tiempo embalsamado. ${ }^{9}$ Como las manos con las que el hombre de la prehistoria dejaba marcas en su gruta. Es el mismo sentimiento, dejar una huella. Quizá esa impronta en el momento, pues no va instigado por la nostalgia en primera instancia, pero con el paso del tiempo lo que queda es eso, la huella de alguien que pasó por ahí. El cine tiene una belleza adicional sobre el video, en el hecho de que en la fotoquímica se abre realmente una huella de la luz. La intimidad con la realidad, es superior a la de los dígitos que se codifican y decodifican en las cámaras digitales. Resiste esa huella de luz del que estuvo enfrente de la cámara. Pero la nostalgia, desde luego no está en las máquinas, está en nosotros. 